\title{
John James Rickard Macleod, M.B., Ch.B., D.Sc., LL.D., F.R.S.
}

Professor MACleod was born at Cluny, near Dunkeld, on September 6, 1876. He was educated at Aberdeen Grammar School and at the University of Aberdeen. After a distinguished undergraduate career he qualified M.B., Ch.B., with Honours, in 1898 and was awarded the Anderson Travelling Fellowship. After a year's work in the Physiology Institute of the University of Leipzig, he was appointed first a Demonstrator in Physiology and later Lecturer in Biochemistry at the London Hospital Medical College, holding at the same time the McKinnon Research Studentship of the Royal Society of London. In 1903 he was appointed Professor of Physiology at the Western Reserve University, Cleveland, Ohio, a post he held until 1918 when he was selected as Professor of Physiology at the University of Toronto. He remained at Toronto until, in I928, he was appointed Regius Professor of Physiology in the University of Aberdeen, a post which he filled with acceptance, despite constant ill-health, until his early death at the age of fifty-eight on March I6, I935.

Macleod's name will always be identified with research work on the metabolism of carbohydrate and more especially with the epoch-making discovery and isolation of insulin. This was no mere chance discovery. Macleod had first-hand knowledge of the whole literature of carbohydrate metabolism in general and of diabetes in particular, he had equally a firsthand knowledge of the necessary experimental technique, and his outlook was catholic. His interest in the fate of carbohydrate in the body began as far back as 1905, and before the experimental work which led ultimately to the discovery of insulin in $192 \mathrm{I}$ was commenced he had published thirty-seven papers on problems relating to the metabolism of carbohydrate. Thus when F. G. Banting came to discuss with him in I92 I the possibility of attacking the problem of obtaining an active extract from the pancreas, using duct-ligated gland, no more helpful and better equipped adviser could have been selected. Macleod encouraged Banting to engage in the research and offered him all the facilities of his laboratory. Banting, in conjunction with C. H. Best, accordingly set to work and obtained within a few months an extract which did exert a beneficial effect on experimental diabetes. This discovery was made public in December I92I. The difficulty which now confronted the investigators 
was that of obtaining a pure reliable substance in sufficient amount. A trained chemist, J. B. Collip, now joined the team, and soon the discovery was made that the active material could be extracted from normal ox pancreas in sufficient amount to render it practicable to treat patients suffering from diabetes mellitus. This discovery has literally saved thousands from an unduly early death. The original idea which started the train of research work and led up to the isolation of insulin was undoubtedly Banting's, but it may be said without fear of contradiction that, if it had not been for the active co-operation of Macleod and others, the result, if it had been attained at all, would certainly not have been attained so quickly. This investigation is one of the best testimonials to the value of team-work directed to a single end which could be selected.

Although the discovery of insulin was an important step in the understanding of the utilisation of carbohydrate in the body, it raised almost as many difficulties as it solved. Almost up to the end of his life Macleod was engaged in an attempt to elucidate many of these new problems.

In addition to his carbohydrate research work Macleod had pursued many other lines of investigation. Between 1899 and 1933 he, either alone or in collaboration, had published nearly two hundred papers. In addition to these papers he also published eleven books, the best known of which are his text-book Physiology and Biochemistry in Modern Medicine, which is now in its seventh edition, Carbohydrate Metabolism and Insulin (1926), and the Fuel of Life (1928). Further, he actively engaged in editorial duties, being, for example, one of the associate editors of Physiological Reviews and of Nutrition Abstracts and Reviews. He also found time to act as Dean of the Faculty of Medicine at Aberdeen and to serve from I929 to I933 on the Medical Research Council.

During his later years Macleod was the recipient of many honours. He was elected a Fellow of the Royal Society of Canada in 1919, of the Royal Society of London in 1923, of the Royal Society of Edinburgh in 1932, and of the Royal College of Physicians of London in 1930, and was elected a member of many foreign learned societies.

In 1923, jointly with F. G. Banting, he was awarded the Nobel Prize in Physiology and Medicine, and in the same year was elected Cameron Prizeman of the University of Edinburgh. In 1928 he was Vanuxem Lecturer at the University of Princeton, and in 1933 Herter Lecturer at Johns Hopkins University, Baltimore.

Macleod was an admirable lecturer, clear, happy, and interesting. As a director of research he was equally good. Although he would not tolerate for an instant careless work, he would listen to any kind of proposal for research work provided the applicant was honest and in earnest.

P.R.S.E.—VOL. LV, 1934-35, PART II. 
He was a sympathetic, enthusiastic leader who inspired devotion. As a man he was endowed with a most attractive personality and had wide interests outside his laboratory work. Honest, loyal, and just himself, he resented intensely all suggestion of chicanery or meanness. He was devoid of affectation and false pride. He was a cheery optimist who met everyone with a happy smile. During his last years, when crippled with arthritis, he required all his optimism. And it did stand him in good stead. These years displayed his true courage and greatness of heart to the utmost. To the very end his serene and happy spirit triumphed. (See also Obituary Notices of Fellows of the Royal Society, No. 4 , 1935, p. 585 .)

E. P. C. 